\title{
Effect of serum from postmenopausal women with osteoporosis exhibiting the Kidney-Yang deficiency pattern on bone formation in an hFOB 1.19 human osteoblastic cell line
}

\author{
YACHAN LI $^{1 *}$, WENNA LIANG ${ }^{1 *}$, XIHAI LI $^{2}$, BIZHEN GAO $^{1}$, HUIJUAN GAN $^{1}$, LIANHUA YIN $^{3}$, \\ JIANYING SHEN ${ }^{1}$, JIE KANG ${ }^{1}$, SHANSHAN DING ${ }^{1}$, XUEJUAN LIN ${ }^{1}$, LINGHONG LIAO ${ }^{1}$ and CANDONG LI ${ }^{1}$ \\ ${ }^{1}$ Research Base of Traditional Chinese Medicine Syndromes; ${ }^{2}$ Academy of Integrative Medicine, Fujian University \\ of Traditional Chinese Medicine, Fuzhou, Fujian 350122; ${ }^{3}$ The Second Affiliated Hospital, \\ Fujian University of Traditional Chinese Medicine, Fuzhou, Fujian 350004, P.R. China
}

Received August 24, 2014; Accepted June 24, 2015

DOI: $10.3892 / \mathrm{etm} .2015 .2616$

\begin{abstract}
The aim of the present study was to investigate the underlying mechanism of the Kidney-Yang deficiency (KYD) pattern of osteoporosis in postmenopausal women of a certain age range by comparing the effect of serum from postmenopausal women with osteoporosis exhibiting the KYD pattern with that of serum from postmenopausal women without osteoporosis on bone formation in an hFOB 1.19 human osteoblastic cell line. A random selection of 30 female, postmenopausal volunteers aged 60-70 years, including 15 cases without osteoporosis and 15 cases with the KYD pattern of osteoporosis, were enrolled at the Physical Examination Center of the Second Affiliated Hospital of Fujian University of Traditional Chinese Medicine. Venous blood was extracted and the serum was separated. The hFOB 1.19 cells were treated with $10 \%$ KYD pattern-serum or control serum from postmenopausal women of the same age range without osteoporosis. It was found that the KYD pattern-serum significantly decreased the cell viability, activity of alkaline phosphatase and number of calcified nodules, as well as downregulated the expression of osteocalcin and osteoprotegerin (OPG) and upregulated that of receptor activator of nuclear factor $\kappa \mathrm{B}$ ligand (RANKL) in the hFOB 1.19 cells. In addition, the present results showed that the concentrations of estradiol $\left(\mathrm{E}_{2}\right), \mathrm{OPG}$ and insulin-like factor-1 (IGF-1) in the KYD pattern-serum were lower than those in the control serum. In combination, these findings
\end{abstract}

Correspondence to: Dr Candong Li, Research Base of Traditional Chinese Medicine Syndromes, Fujian University of Traditional Chinese Medicine, 1 Qiuyang Road, Fuzhou, Fujian 350122, P.R. China

E-mail: fjzylcd@126.com

${ }^{*}$ Contributed equally

Key words: bone formation, osteoblast, postmenopausal osteoporosis, Kidney-Yang deficiency pattern suggest that the downregulation of $E_{2}$, OPG and IGF-1 in the KYD pattern-serum inhibits the OPG/RANKL system, leading to a decrease in bone formation in the hFOB 1.19 cells. This indicates that the alterations in $\mathrm{E}_{2}$, OPG and IGF-1 may account for the susceptibility of certain postmenopausal women to the KYD pattern of osteoporosis.

\section{Introduction}

Postmenopausal osteoporosis (PMO), a common disease characterized by bone reduction and microarchitectural deterioration of the bone, has a serious effect on the quality of life of the patients, particularly the elderly $(1,2)$. PMO is considered to be the result of an imbalance between bone resorption and formation, which are regulated by osteoclasts and osteoblasts, respectively. This imbalance leads to increased bone fragility and susceptibility to fractures (3-5). The mechanism underlying the pathogenesis of PMO is multifactorial and complicated. Gonadal steroids play an important role in bone remodeling and skeletal structure maintenance (6-8).

According to Traditional Chinese Medicine (TCM) theory, PMO can be classified into different TCM patterns (Zheng), including the Kidney-Yang deficiency (KYD), Kidney-Yin deficiency and Kidney-Yin and Yang deficiency patterns (9-11). Zheng, the body's overall response to different factors in the evolution of a disease, is intrinsically linked to a group of signs and symptoms at a certain stage of the disease $(12,13)$. Zheng is based on factors including pulse feeling and tongue appearance and can be used as a guideline in TCM disease classification; however, it is not simply a collection of disease symptoms but rather can be defined as the TCM theoretical abstraction of the symptom profiles of patients (14-16). The KYD pattern (Shen-Yang-Xu Zheng) is an important syndrome of PMO (17); while some postmenopausal women are prone to forming the KYD pattern of osteoporosis, others of the same age group exhibit no development of osteoporosis. The underlying mechanism of this phenomenon remains to be elucidated. We hypothesized that the serum taken from patients with the KYD pattern of osteoporosis contains bioactive molecules in the metabolic products of the disease. The collection of this 
serum is easy, and the serum can be used to objectively imitate the interaction between the serum and cells, thus generating an effective approach for the mechanistic study of the disease. In the present study, the susceptibility of certain postmenopausal women of the same age group to the KYD pattern of osteoporosis, as well as the associated underlying mechanism, was investigated.

\section{Materials and methods}

Ethics statement. Ethical approval for the present study was obtained from the Clinical Trial Ethics Committee of the Second Affiliated Hospital of Fujian University of TCM (Fuzhou, China), and written informed consent was obtained from all participants prior to the experiment.

Participants. A random selection of 30 postmenopausal female volunteers aged 60-70 years, including 15 women with and 15 without osteoporosis, was enrolled in the study from the Physical Examination Center of the Second Affiliated Hospital of Fujian University of TCM. The diagnosis of PMO was defined by a bone mineral density (BMD) T-score of $\geq 2.5$ standard deviations below the young normal gender-matched BMD of the reference database, in accordance with the World Health Organization criteria (18). Participants receiving any medications known to affect the calcium or bone metabolism, such as current use or history of a $\geq 3$-month use of exogenous estrogens, thiazine or corticosteroids, were excluded from the study. Participants with any other disorder known to affect bone metabolism were also excluded.

The TCM diagnosis of the participants was based on the information obtained from four diagnostic processes, including looking, smelling, asking and touching. The diagnostic criteria of the KYD pattern included a sensation of cold and aching in the loins and knees, cold limbs and body, sexual hypoesthesia, infertility due to cold in the uterus, dispiritedness and lassitude, early morning diarrhea or frequent micturition, clear and profuse urine, profuse nocturnal urine, loose stools, bright whitish or blackish complexion and a light-colored tongue with white fur, as well as a deep and weak pulse (19).

Serum preparation. Venous blood was collected in the morning between 8:00 and 9:00 a.m. and centrifuged for $10 \mathrm{~min}$ at 1,200 x $\mathrm{g}$ within $30 \mathrm{~min}$, and the serum was separated and stored at $-80^{\circ} \mathrm{C}$.

Cell culture. An hFOB 1.19 human osteoblastic cell line from the Institute of Biochemistry and Cell Biology (Chinese Academy of Sciences, Shanghai, China) was cultured in Dulbecco's modified Eagle's medium (Gibco-BRL, Grand Island, NY, USA), supplemented with $10 \%(\mathrm{v} / \mathrm{v})$ fetal bovine serum (FBS) (Gibco-BRL), penicillin $(100 \mathrm{U} / \mathrm{ml})$ and streptomycin $(100 \mu \mathrm{g} / \mathrm{ml})$ at $37^{\circ} \mathrm{C}$ in humidified incubator with $5 \% \mathrm{CO}_{2}$. When the cells reached $80 \%$ confluence, they were harvested with $0.25 \%$ trypsin-EDTA solution and then seeded in 96- and 12-well plates at a density of $6 \times 10^{3}$ and $1 \times 10^{5}$ cells/well, respectively, in a medium of $10 \%$ FBS. Twenty-four hours after stabilization, the cells were washed in phosphate-buffered saline solution twice and treated with the KYD pattern-serum or control serum from postmenopausal women without osteoporosis.
Analysis of cell viability using MTT assay. The cells were treated with $10 \%$ KYD pattern-serum for different periods of time. The medium was discarded and replaced with $10 \mu 1 \mathrm{MTT}$ (Sigma-Aldrich, St. Louis, MO, USA) at $37^{\circ} \mathrm{C}$ for $4 \mathrm{~h}$ and then $100 \mu \mathrm{l}$ dimethylsulfoxide was added. The absorbance at $490 \mathrm{~nm}$ was measured on an ELISA reader (Model EXL800; BioTek Instruments, Inc., Winooski, VT, USA).

Alkaline phosphatase (ALP) activity assay. Following treatment with the KYD pattern-serum for $72 \mathrm{~h}$, the cells were lysed with $0.05 \%$ Triton X-100 (Amresco, Inc., Solon, USA). The activity of ALP was determined by the conversion of $p$-nitrophenyl phosphate to $p$-nitrophenol using a commercial kit (Nanjing Jiancheng Biological Technology Co., Ltd., Nanjing, China). The total protein concentration was evaluated with a bicinchoninic acid protein assay kit (Bio-Rad, Hercules, CA, USA). An equal quantity of protein was mixed with $100 \mu \mathrm{l}$ substrate at $37^{\circ} \mathrm{C}$ for $15 \mathrm{~min}$ and $80 \mu \mathrm{l}$ reaction-stop solution was added. The results were determined at $405 \mathrm{~nm}$. The absorbance was normalized based on the protein content.

Alizarin red S staining for mineralization. Calcified nodules of the hFOB 1.19 cells treated with $10 \%$ KYD pattern-serum were demonstrated by Alizarin red S staining. The cells were seeded into 48 -well plates at a density of $2 \times 10^{5}$ cells per well. The cells were subsequently treated with $10 \%$ KYD pattern-serum for 14 days and then fixed with $0.5 \mathrm{ml} /$ well formalin:methanol: $\mathrm{H}_{2} \mathrm{O}$ $(1: 1: 1.5)$ for $30 \mathrm{~min}$ at room temperature. The cells were stained with $0.1 \%$ Alizarin red S (Sigma-Aldrich) at $37^{\circ} \mathrm{C}$ for $30 \mathrm{~min}$ and images of the stained calcified nodules were captured using microscopy.

$R N A$ extraction and reverse transcription-quantitative polymerase chain reaction ( $R T-q P C R)$ analysis. Total RNA from the cells was isolated using TRIzol ${ }^{\circledR}$ reagent (Invitrogen Life Technologies, Carlsbad, CA, USA). RT was performed using random primers and the SuperScript ${ }^{\mathrm{TM}}$ III First-Strand Synthesis system (Invitrogen Life Technologies). qPCR was conducted in an ABI Prism 7700 Sequence Detection System using the SYBR ${ }^{\circledR}$ Green PCR Master Mix (Invitrogen Life Technologies). The sequences of the PCR primers for the amplification of the ALP, osteocalcin, osteoprotegerin (OPG), receptor activator of nuclear factor $\kappa B$ ligand (RANKL) and GAPDH transcripts were as follows: ALP forward, 5'-AGC CCTTCACTGCCATCCTGT-3' and reverse, 5'-ATTCTCTCG TTCACCGCCCAC-3', 68 bp; osteocalcin forward, 5'-CAA AGGTGCAGCCTTTGTGTC-3' and reverse, 5'-TCACAG TCCGGATTGAGCTCA-3', 150 bp; OPG forward, 5'-AGT ACGTCAAGCAGGAGTGCAAT-3' and reverse, 5'-CCAGCT TGCACCACTCCAA-3', 129 bp; RANKL forward, 5'-AGA GCGCAGATGGATCCTAA-3' and reverse, 5'-TTCCTTTTG CACAGCTCCTT-3', 180 bp; GAPDH forward, 5'-CAACTA CATGGTTTACATGTTC-3' and reverse, 5'-GCCAGTGGA CTCCACGAC-3', 163 bp. The amplification protocol was as follows: Denaturation at $95^{\circ} \mathrm{C}$ for $10 \mathrm{~min}$ and 40 cycles of $95^{\circ} \mathrm{C}$ for $20 \mathrm{sec}, 57^{\circ} \mathrm{C}$ for $10 \mathrm{sec}$, and $72^{\circ} \mathrm{C}$ for $30 \mathrm{sec}$. The amplification and melting curve data were collected. Fold-changes of the genes expression were estimated according to the comparative $2^{-\Delta \Delta \mathrm{Ct}}$ method. 


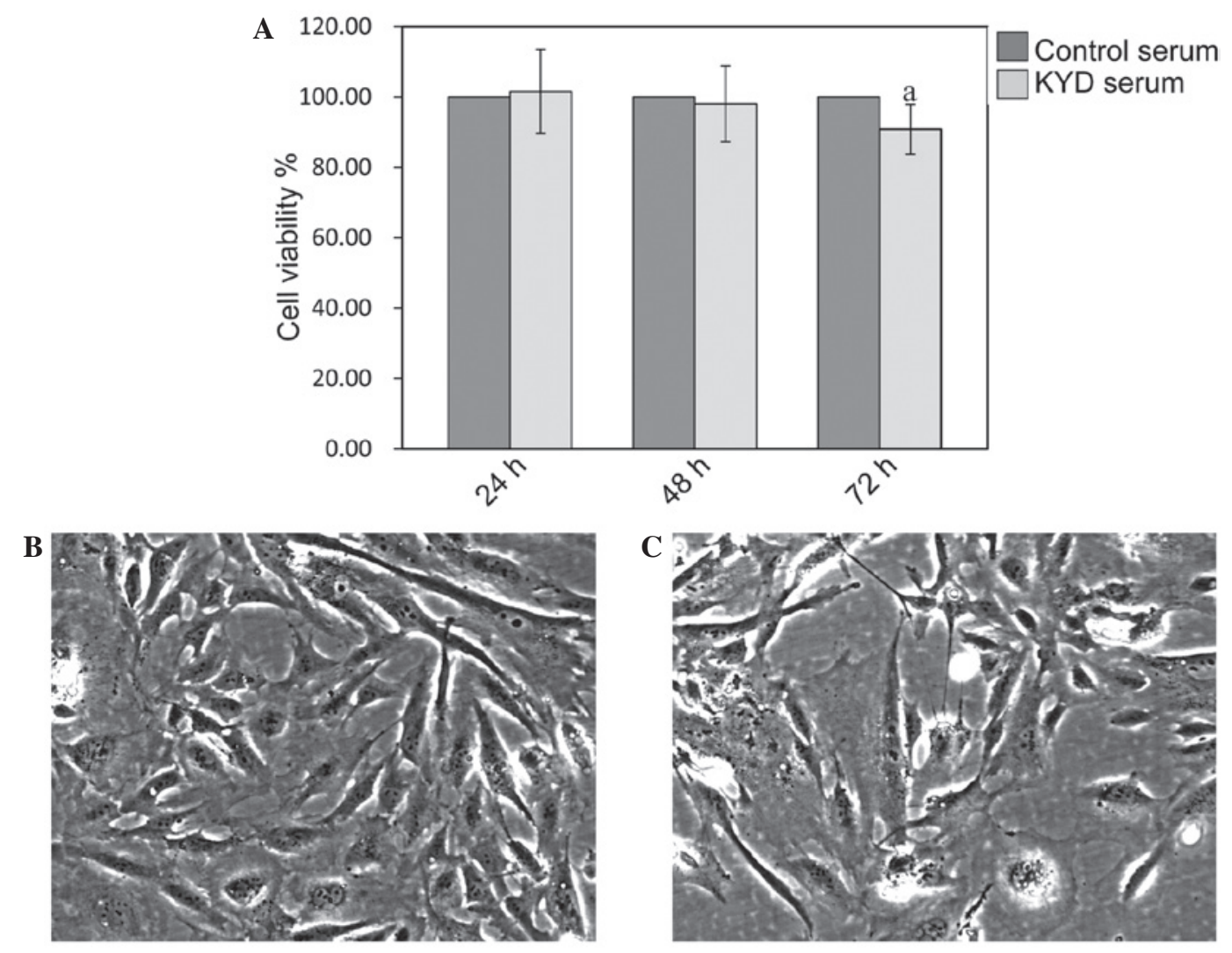

Figure 1. KYD pattern-serum inhibits cell viability. (A) The viability of hFOB 1.19 cells was determined via MTT assay, and a statistically significant difference was observed between the cells treated with the KYD pattern-serum and those treated with control serum for $72 \mathrm{~h}$ (magnification, x200). Data are presented as the mean \pm standard deviation (error bars) from at least three independent experiments. ${ }^{\mathrm{a}} \mathrm{P}<0.05$, significant vs. control serum. (B and C) Morphology of hFOB 1.19 cells treated with the (B) KYD pattern-serum and (C) control serum for $72 \mathrm{~h}$. KYD, Kidney-Yang deficiency.

Western blot analysis. Total cellular protein was extracted from the cells using radioimmunoprecipitation assay buffer (Beyotime Biotechnology Co., Ltd., Shanghai, China), and the total protein concentration was determined using a Bio-Rad protein assay. Equal quantities of protein were separated using SDS-PAGE and transferred onto polyvinylidene fluoride membranes (Invitrogen Life Technologies). The blots were blocked with 5\% skimmed milk powder (Sigma-Aldrich) for $2 \mathrm{~h}$ at room temperature and were incubated with rabbit polyclonal antibodies against osteocalcin (1:800; sc-30044), OPG $(1: 1,000 ;$ sc-11383), RANKL (1:800; sc-9073) and $\beta$-actin (1:1,000; sc-130657) antibodies (Santa Cruz Biotechnology Inc., Santa Cruz, CA, USA) overnight at $4^{\circ} \mathrm{C}$ followed by a goat anti-rabbit horseradish peroxidase (HRP)-conjugated secondary antibody IgG (1:10,000; ZB-2301; Zhongshan Golden Bridge Biotechnology Co., Ltd., Beijing, China) at room temperature for $1 \mathrm{~h}$. The immunoreactive proteins were visualized using Western Blot Chemiluminescence Luminol Reagent (Santa Cruz Biotechnology, Inc.). Immunoblot bands were quantified using the Tocan 190 protein assay system (Bio-Rad). $\beta$-actin was used as the loading control.

ELISA. The serum concentration of estradiol $\left(\mathrm{E}_{2}\right), \mathrm{OPG}$, and insulin-like growth factor 1 (IGF-1) was assessed using ELISA (Shanghai Jinma Biological Technology Co., Ltd, Shanghai, China). All commercial assays were performed according to the manufacturer's instructions. Briefly, ELISA plates were percolated with mouse anti-human immunoglobulin G, and standards, and samples were loaded into the wells and incubated for $1 \mathrm{~h}$ at room temperature. HRP-conjugated anti-human $\mathrm{E}_{2}$, OPG and IGF-1 detection antibodies were added and incubated at room temperature for $1 \mathrm{~h}$. The reaction was visualized through color development and the absorbance (optical density) was measured at a $450-\mathrm{nm}$ wavelength on an ELISA reader (Model EXL800; BioTek Instruments, Inc.). The conversion of optical density units for the study samples to concentration was achieved through a computer software-mediated comparison with a standard curve using the KC Junior (BioTek Instruments, Inc.).

Statistical analysis. Data were analyzed using the SPSS 19.0 software for Windows (IBM SPSS, Armonk, NY, USA). The quantitative data are expressed as the mean \pm standard deviation. The statistical analysis of the data was performed using nonparametric tests for two independent samples. $\mathrm{P}<0.05$ was considered to indicate a statistically significant difference.

\section{Results}

KYD pattern-serum inhibits cell viability of the $h F O B 1.19$ cells. As shown in Fig. 1A, the viability of the hFOB 1.19 cells was not affected by treatment with the KYD pattern-serum at 24 and $48 \mathrm{~h}(\mathrm{P}>0.05)$, but was significantly decreased at $72 \mathrm{~h}(\mathrm{P}=0.025)$, compared with the viability of cells treated with control serum. Cells treated with the KYD pattern-serum decreased in number following treatment and underwent 

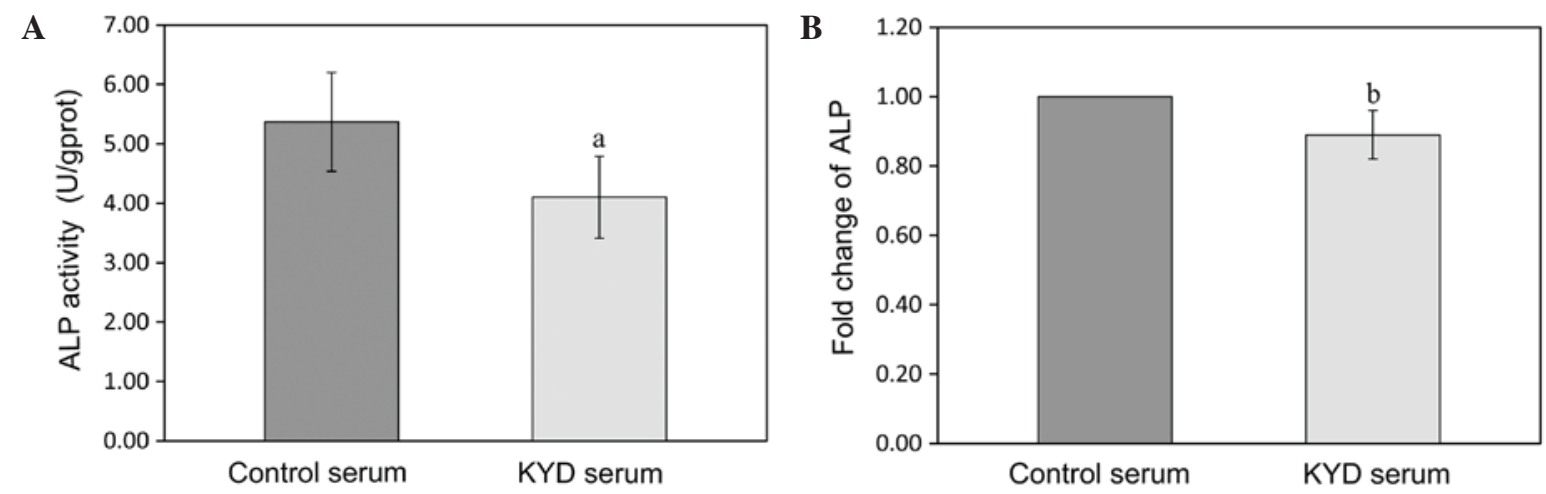

Figure 2. KYD pattern-serum decreases ALP activity and mRNA expression in the hFOB 1.19 cells. The hFOB 1.19 cells were treated with the KYD pattern-serum for $72 \mathrm{~h}$, and the (A) ALP activity and (B) mRNA expression were measured. Data are presented as the mean \pm standard deviation (error bars) from at least three independent experiments. ${ }^{\mathrm{a}} \mathrm{P}<0.05$ and ${ }^{\mathrm{b}} \mathrm{P}<0.01 \mathrm{vs}$. control serum. ALP, alkaline phosphatase; KYD, Kidney-Yang deficiency.
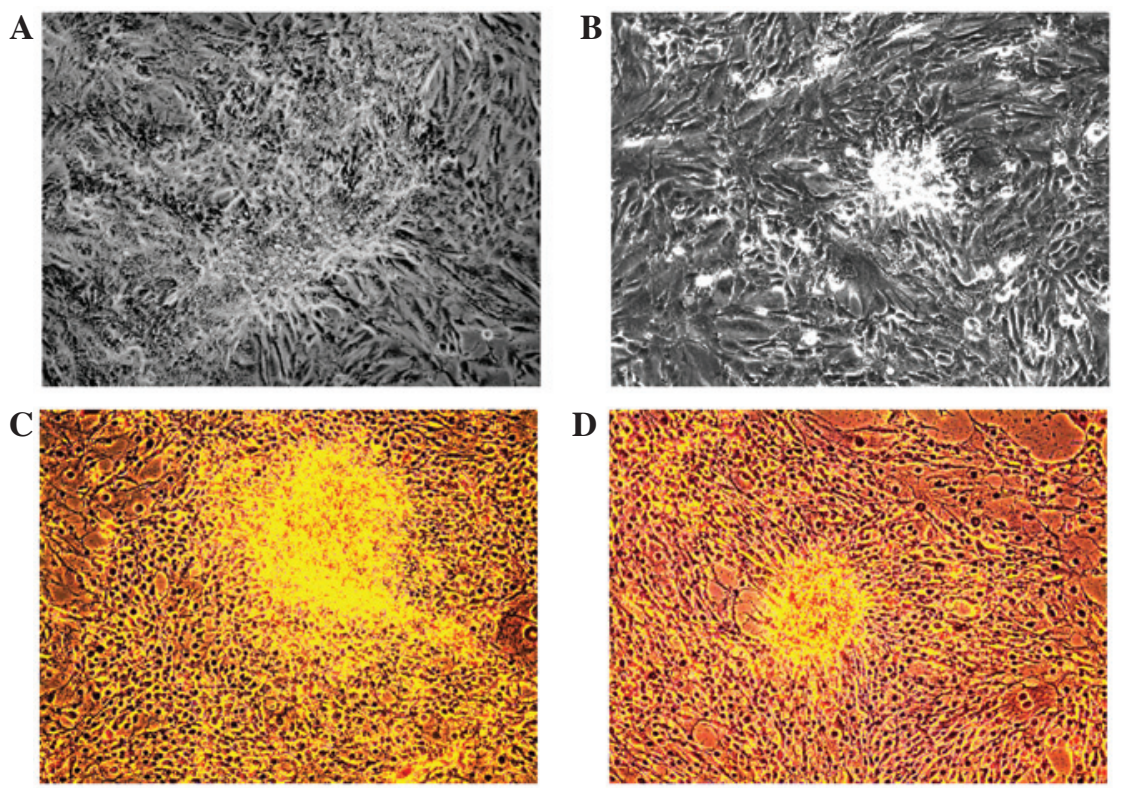

Figure 3. Effect of the KYD pattern-serum on calcified nodules in hFOB 1.19 cells (magnification, x100). (A and B) Cultivation of cells on day 14; the hFOB 1.19 cells were treated with the (A) KYD pattern-serum or (B) control serum for 14 days. (C and D) Alizarin red S staining for calcified nodules: (C) KYD pattern-serum-treated cells and (D) control serum-treated cells. KYD, Kidney-Yang deficiency.

morphological changes (Fig. 1B and C), including cell size and shape, indicating that the KYD pattern-serum inhibited the osteoblast viability significantly, contributing to the progression of bone loss in PMO.

KYD pattern-serum decreases ALP activity and $m R N A$ expression in the hFOB 1.19 cells. The activity of ALP was downregulated in the hFOB 1.19 cells treated with the KYD pattern-serum, compared with that in the cells treated with control serum ( $\mathrm{P}=0.037$ ) (Fig. 2A). qPCR also showed that the mRNA expression of ALP was clearly decreased following treatment with the KYD pattern-serum compared with that following treatment with control serum $(\mathrm{P}=0.008)$ (Fig. 2B). The calcified nodules appeared bright red in color following Alizarin red S staining (Fig. 3A-D). The KYD pattern-serum could significantly inhibit the formation of calcified nodules compared with the control serum, which suggests that the KYD pattern-serum reduced bone formation.
KYD pattern-serum downregulates the expression of osteocalcin and $O P G$ and upregulates the expression of RANKL in the $h F O B 1.19$ cells. In order to further explore the mechanism of the KYD pattern in bone formation, the mRNA and protein expression of osteocalcin, OPG and RANKL was analyzed following KYD pattern-serum treatment using RT-qPCR and western blotting, respectively. The protein levels of osteocalcin and OPG in the hFOB 1.19 cells treated with the KYD pattern-serum were downregulated $(\mathrm{P}=0.047$ and $\mathrm{P}=0.009)$, and the protein level of RANKL was upregulated $(\mathrm{P}=0.006)$, compared with the protein levels following treatment with control serum (Fig. 4A-D). The changes in the mRNA expression of osteocalcin, OPG and RANKL following treatment with the KYD pattern-serum were similar to the changes in the protein levels (Fig. 4E-G) $(\mathrm{P}=0.002, \mathrm{P}<0.001$ and $\mathrm{P}=0.004$ versus control, respectively), which suggested that the KYD pattern-serum regulated the bone metabolism via the OPG/RANKL system. 

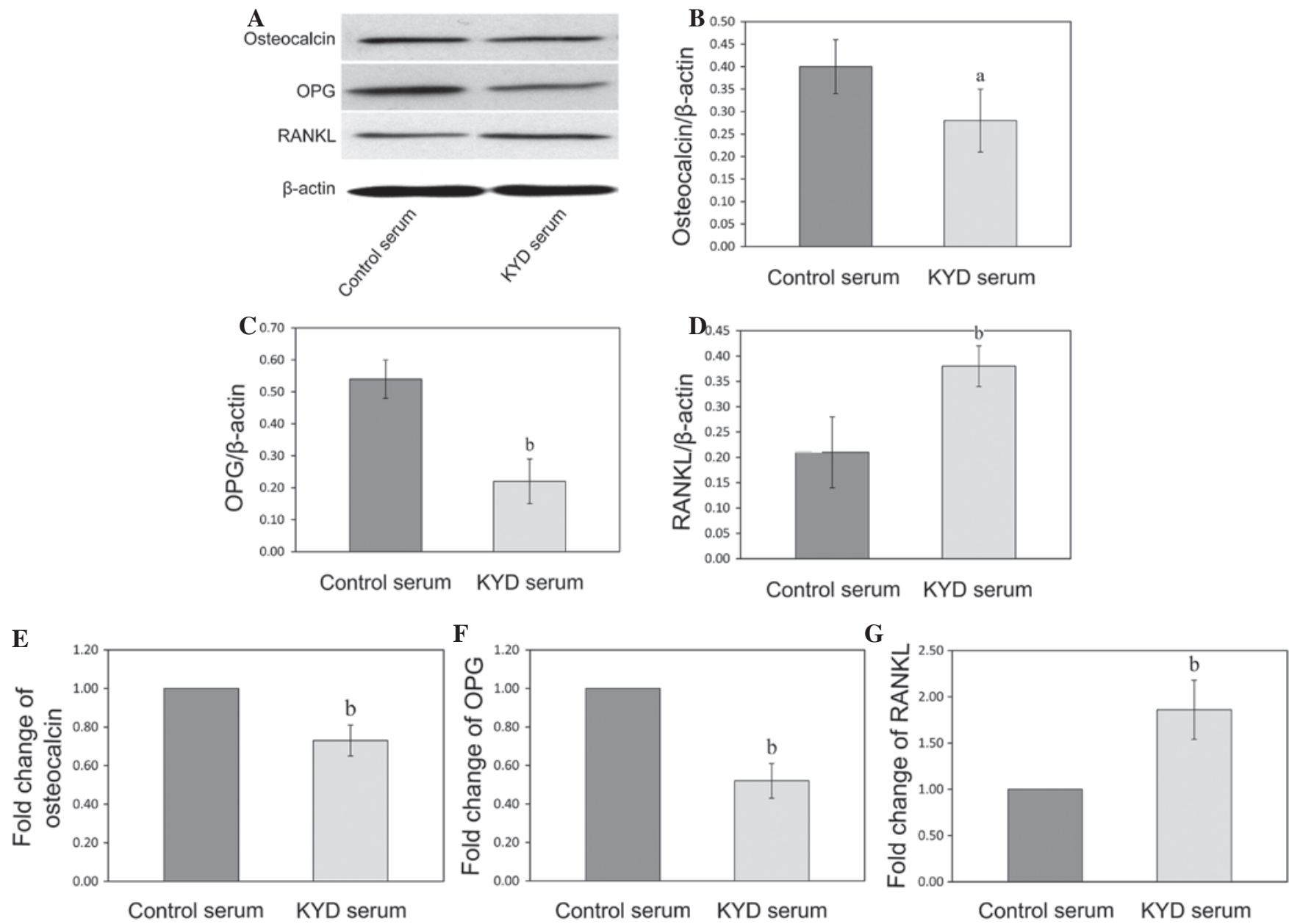

Figure 4. Effect of KYD pattern-serum on the expression of osteocalcin, OPG and RANKL. Total protein was isolated from the hFOB 1.19 cells treated with the KYD pattern-serum for $72 \mathrm{~h}$, and (A) western blotting was performed in order to determine the protein levels of (B) osteocalcin, (C) OPG and (D) RANKL, which were normalized to the levels of $\beta$-actin. Total RNA was isolated and the quantitative polymerase chain reaction was performed to determine the mRNA expression of (E) osteocalcin, (F) OPG and (G) RANKL, which was normalized to that of GAPDH. Data are presented as the mean \pm standard deviation (error bars) from at least three independent experiments. ${ }^{\mathrm{P}} \mathrm{P}<0.05$ and ${ }^{\mathrm{b}} \mathrm{P}<0.01$ vs. control serum. KYD, Kidney-Yang deficiency; OPG, osteoprotegerin; RANKL, receptor activator of nuclear factor $\kappa \mathrm{B}$ ligand.
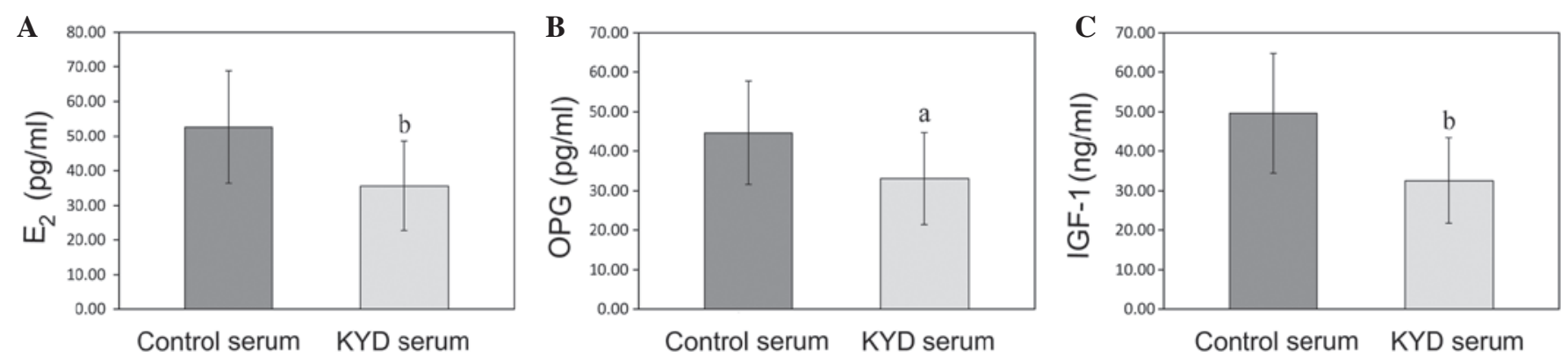

Figure 5. Concentrations of $\mathrm{E}_{2}$, OPG and IGF-1 in the KYD pattern-serum and control serum. (A-C) The concentrations of (A) $\mathrm{E}_{2}$, (B) OPG and (C) IGF-1 in the KYD pattern- and control serums were assessed by ELISA. Data are presented as the mean \pm standard deviation (error bars). ${ }^{\mathrm{P}} \mathrm{P}<0.05$ and ${ }^{\mathrm{b}} \mathrm{P}<0.01 \mathrm{Vs}$. control serum. $\mathrm{E}_{2}$, estradiol; OPG, osteoprotegerin; IGF-1, insulin-like growth factor-1; KYD, Kidney-Yang deficiency.

Downregulation of $E_{2}, O P G$ and IGF-1 in the KYD pattern-serum leads to an inhibition of bone formation in the $h F O B 1.19$ cells. In order to obtain some insight into the underlying mechanism of the inhibition of bone formation by the KYD pattern-serum, the concentrations of $\mathrm{E}_{2}, \mathrm{OPG}$ and IGF-1 in the KYD pattern- and control serums were analyzed.
As shown in Fig. 5A-C, the concentrations of $\mathrm{E}_{2}$, OPG and IGF-1 in the KYD pattern-serum were lower than those in the control serum $(\mathrm{P}=0.003, \mathrm{P}=0.012$ and $\mathrm{P}=0.001$, respectively), indicating that the alteration in the serum levels of $E_{2}$, OPG and IGF-1 may be responsible for the formation of the KYD pattern in postmenopausal women. 


\section{Discussion}

According to TCM theory, the kidney regulates bone formation and development. Kidney deficiency leading to bone loss is associated with the pathological process of PMO $(17,20,21)$. Among all kidney deficiency patterns, the KYD pattern is a common clinical type of PMO; however, the precise mechanism behind its formation remains unclear. The present results revealed that alterations in $\mathrm{E}_{2}$, OPG and IGF-1 may account for the susceptibility of certain postmenopausal women to the KYD pattern of osteoporosis.

Using the MTT assay, it was shown that the KYD pattern-serum significantly inhibited the viability of the hFOB 1.19 cells, suggesting that it also inhibited the proliferation of these cells. The possibility of the KYD pattern-serum controlling the mineralization of osteoblasts was explored by measuring the ALP activity, osteocalcin expression and formation of calcified nodules in the hFOB 1.19 cells. ALP, a classic biomarker of osteoblast cell differentiation, plays a crucial role in the early stage of extracellular matrix mineralization $(22,23)$. When cultured in appropriate osteogenic media, osteoblastic cells form a calcified extracellular compartment and express osteocalcin; thus calcified nodules are indicative of osteoblast differentiation and mineralization $(24,25)$. In the present study, it was found that the KYD pattern-serum significantly decreased the ALP activity and formation of calcified nodules and downregulated the expression of osteocalcin. It has been reported that, in PMO patients, the altered bone microarchitecture and low BMD result in an increased risk of bone fractures due to decreased proliferation and mineralization of osteoblasts $(26,27)$, and the results of the present study were in accordance with this conclusion.

Previous studies showing that OPG mediates bone formation and RANKL mediates bone resorption have enhanced the understanding of bone remodeling regulation (28-30). A number of studies have suggested that the binding of RANKL to RANK results in the activation of signaling pathways, which control the function of osteoclasts; however, OPG protects the bones from excessive resorption by inhibiting the binding of RANKL to RANK (31-33). In order to investigate the effects of the KYD pattern-serum on the OPG/RANKL system in the hFOB 1.19 cells, the expression of OPG and RANKL was examined. The present results showed that the KYD pattern-serum could reduce bone formation through the downregulation of OPG and upregulation of RANKL.

The risk of PMO develops increasingly with estrogen deficiency, which causes a series of changes in the blood and interrupts the balance between bone formation and resorption (34). The suppression of $E_{2}$, OPG and IGF-1 production is closely associated with an increase in bone turnover and an accelerated bone loss, as shown by a decrease in the BMD $(35,36)$. IGF-1, a growth-promoting polypeptide that is essential for normal growth and development directly regulates bone growth and density; therefore, the possibility that the changes in the serum levels of $\mathrm{E}_{2}$, OPG and IGF-1 could account for the formation of the KYD pattern was explored in the present study by measuring the concentrations of $E_{2}$, OPG and IGF-1 in the KYD pattern-serum and control serum. The findings showed that the concentrations of $\mathrm{E}_{2}, \mathrm{OPG}$ and IGF-1 were downregulated in the KYD pattern-serum, compared with those in the control serum. Although it is clear that the alterations in the $\mathrm{E}_{2}$, OPG and IGF-1 serum levels affect bone formation, the other proteins in the serum may also play a crucial role in bone remodeling and therefore warrant future investigation.

In conclusion, the present study has provided data showing that the alterations in the concentrations of $\mathrm{E}_{2}, \mathrm{OPG}$ and IGF-1 may account for the susceptibility of certain postmenopausal women to the KYD pattern of osteoporosis by inhibiting the OPG/RANKL system, which leads to a reduction in bone formation. The major limitation of this study was the small sample size, and thus a randomized, controlled trial with a larger sample size needs to be conducted. Furthermore, the fact that the KYD pattern-serum was the only pattern of kidney deficiency investigated, with regard to its effects on the function of osteoblasts, could be considered one-sided; therefore experiments on the other patterns will be carried out in the future.

\section{Acknowledgements}

This study was supported by the National Natural Science Foundation of China (grant nos. 81202645 and 81230087), and the Natural Science Foundation of Fujian Province (grant no. 2015J01339).

\section{References}

1. Reid IR: Should we prescribe calcium supplements for osteoporosis prevention? J Bone Metab 21: 21-28, 2014.

2. Lagari VS and Levis S: Phytoestrogens in the prevention of postmenopausal bone loss. J Clin Densitom 16: 445-449, 2013.

3. Liang W, Lin M, Li X, Li C, Gao B, Gan H, Yang Z, Lin X, Liao $\mathrm{L}$ and Yang M: Icariin promotes bone formation via the BMP-2/Smad4 signal transduction pathway in the hFOB 1.19 human osteoblastic cell line. Int J Mol Med 30: 889-895, 2012.

4. Hayden RS, Quinn KP, Alonzo CA, Georgakoudi I and Kaplan DL: Quantitative characterization of mineralized silk film remodeling during long-term osteoblast-osteoclast co-culture. Biomaterials 35: 3794-3802, 2014.

5. Huang S, Eleniste PP, Wayakanon K, Mandela P, Eipper BA, Mains RE, Allen MR and Bruzzaniti A: The Rho-GEF Kalirin regulates bone mass and the function of osteoblasts and osteoclasts. Bone 60: 235-245, 2014.

6. Zhao R: Immune regulation of bone loss by Th17 cells in oestrogen-deficient osteoporosis. Eur J Clin Invest 43: 1195-1202, 2013.

7. Frenkel B, Hong A, Baniwal SK, Coetzee GA, Ohlsson C, Khalid $\mathrm{O}$ and Gabet Y: Regulation of adult bone turnover by sex steroids. J Cell Physiol 224: 305-310, 2010.

8. Baek KH, Oh KW, Lee WY, et al: Changes in the serum sex steroids, IL-7 and RANKL-OPG system after bone marrow transplantation: Influences on bone and mineral metabolism. Bone 39: 1352-1360, 2006.

9. Cheng M, Wang Q, Fan Y, Liu X, Wang L, Xie R, Ho CC and Sun W: A traditional Chinese herbal preparation, Er-Zhi-Wan, prevent ovariectomy-induced osteoporosis in rats. J Ethnopharmacol 138: 279-285, 2011.

10. $\mathrm{Xu} \mathrm{H}$ and Lawson $\mathrm{D}$ : Theories and practice in prevention and treatment principles in relation to Chinese herbal medicine and bone loss. J Tradit Chin Med 24: 88-92, 2004.

11. Damiani G: The Yin and Yang of anti-Darwinian epigenetics and Darwinian genetics. Riv Biol 100: 361-402, 2007.

12. Wang $\mathrm{P}$ and Chen Z: Traditional Chinese medicine ZHENG and Omics convergence: A systems approach to post-genomics medicine in a global world. OMICS 17: 451-459, 2013.

13. Jiang M, Lu C, Zhang C, Yang J, Tan Y, Lu A and Chan K: Syndrome differentiation in modern research of traditional Chinese medicine. J Ethnopharmacol 140: 634-642, 2012.

14. Lu A, Jiang M, Zhang C and Chan K: An integrative approach of linking traditional Chinese medicine pattern classification and biomedicine diagnosis. J Ethnopharmacol 141: 549-556, 2012. 
15. Li S, Zhang ZQ, Wu LJ, Zhang XG, Li YD and Wang YY: Understanding ZHENG in traditional Chinese medicine in the context of neuro-endocrine-immune network. IET Syst Biol 1: $51-60,2007$.

16. Jiang M, Zha Q, Lu C, He Y and Lu A: Association between tongue appearance in Traditional Chinese Medicine and effective response in treatment of rheumatoid arthritis. Complement Ther Med 19: 115-121, 2011.

17. Liang W, Li X, Li Y, Li C, Gao B, Gan H, Li S, Shen J, Kang J, Ding $\mathrm{S}$, et al: Tongue coating microbiome regulates the changes in tongue texture and coating in patients with post-menopausal osteoporosis of Gan-shen deficiency syndrome type. Int J Mol Med 32: 1069-1076, 2013.

18. Méndez JP, Rojano-Mejía D, Pedraza J, Coral-Vázquez RM, Soriano R, García-García E, Aguirre-García Mdel C, Coronel $\mathrm{A}$ and Canto P: Bone mineral density in postmenopausal Mexican-Mestizo women with normal body mass index, overweight, or obesity. Menopause 20: 568-572, 2013.

19. An S, Li E and Tong X: Study on relationship between estrogen receptor gene polymorphism and syndrome differentiation typing of female postmenopausal osteoporosis in Traditional Chinese medicine. Zhongguo Zhong Xi Yi Jie He Za Zhi 20 907-910, 2000 (In Chinese).

20. Leung PC and Siu WS: Herbal treatment for osteoporosis: A current review. J Tradit Complement Med 3: 82-87, 2013.

21. Gao Z, Lu Y, Halmurat Upur, Jing J and Xu D: Study of osteoporosis treatment principles used historically by ancient physicians in Chinese Medicine. Chin J Integr Med 19: 862-868, 2013.

22. Matsumoto Y, Otsuka F, Takano-Narazaki M, Katsuyama T, Nakamura E, Tsukamoto N, Inagaki K, Sada KE and Makino H: Estrogen facilitates osteoblast differentiation by upregulating bone morphogenetic protein-4 signaling. Steroids 78: 513-520, 2013.

23. Coelho MJ and Fernandes MH: Human bone cell cultures in biocompatibility testing. Part II: Effect of ascorbic acid, beta-glycerophosphate and dexamethasone on osteoblastic differentiation. Biomaterials 21: 1095-1102, 2000.

24. Melville KM, Kelly NH, Khan SA, Schimenti JC, Ross FP, Main RP and van der Meulen MC: Female mice lacking estrogen receptor-alpha in osteoblasts have compromised bone mass and strength. J Bone Miner Res 29: 370-379, 2014

25. Parker BD, Bauer DC, Ensrud KE and Ix JH: Association of osteocalcin and abdominal aortic calcification in older women: The study of osteoporotic fractures. Calcif Tissue Int 86: 185-191, 2010.
26. Sapir-Koren $\mathrm{R}$ and Livshits G: Is interaction between age-dependent decline in mechanical stimulation and osteocyte-estrogen receptor levels the culprit for postmenopausal-impaired bone formation? Osteoporos Int 24: 1771-1789, 2013.

27. Oh SM, Kim HR and Chung KH: Effects of ginkgo biloba on in vitro osteoblast cells and ovariectomized rat osteoclast cells. Arch Pharm Res 31: 216-224, 2008.

28. Botella S, Restituto P, Monreal I, Colina I, Calleja A and Varo N: Traditional and novel bone remodeling markers in premenopausal and postmenopausal women. J Clin Endocrinol Metab 98: E1740-E1748, 2013.

29. Stuss M, Rieske P, Cegłowska A, Stêpień-Kłos W, Liberski PP, Brzeziańska E and Sewerynek E: Assessment of OPG/RANK/RANKL gene expression levels in peripheral blood mononuclear cells (PBMC) after treatment with strontium ranelate and ibandronate in patients with postmenopausal osteoporosis. J Clin Endocrinol Metab 98: E1007-E1011, 2013.

30. Shoji S, Tabuchi M, Miyazawa K, Yabumoto T, Tanaka M, Kadota M, Maeda $\mathrm{H}$ and Goto S: Bisphosphonate inhibits bone turnover in OPG (-/-) mice via a depressive effect on both osteoclasts and osteoblasts. Calcif Tissue Int 87: 181-192, 2010.

31. Mazière C, Salle V, Gomila $\mathrm{C}$ and Mazière JC: Oxidized low density lipoprotein enhanced RANKL expression in human osteoblast-like cells. Involvement of ERK, NFkappaB and NFAT. Biochim Biophys Acta 1832: 1756-1764, 2013.

32. Yasuda H: RANKL, a necessary chance for clinical application to osteoporosis and cancer-related bone diseases. World J Orthop 4: 207-217, 2013.

33. Aubin JE and Bonnelye E: Osteoprotegerin and its ligand: A new paradigm for regulation of osteoclastogenesis and bone resorption. Osteoporos Int 11: 905-913, 2000.

34. Mozaffari-Khosravi H, Hesabgar HA, Owlia MB, Hadinedoushan $\mathrm{H}$, Barzegar $\mathrm{K}$ and Fllahzadeh MH: The effect of garlic tablet on pro-inflammatory cytokines in postmenopausal osteoporotic women: A randomized controlled clinical trial. J Diet Suppl 9: 262-271, 2012.

35. Yakar S, Rosen CJ, Beamer WG, Ackert-Bicknell CL, Wu Y, Liu JL, Ooi GT, Setser J, Frystyk J, Boisclair YR, et al: Circulating levels of IGF-1 directly regulate bone growth and density. J Clin Invest 110: 771-781, 2002.

36. Papierska L, Rabijewski M, Kasperlik-Załuska A and Zgliczyński W: Effect of DHEA supplementation on serum IGF-1, osteocalcin and bone mineral density in postmenopausal, glucocorticoid-treated women. Adv Med Sci 57: 51-57, 2012. 